\title{
Assessing the antibiotic potential of essential oils against Haemophilus ducreyi
}

\author{
Zachary Lindeman, Molly Waggoner, Audra Batdorff and Tricia L Humphreys*
}

\begin{abstract}
Background: Haemophilus ducreyi is the bacterium responsible for the genital ulcer disease chancroid, a cofactor for the transmission of HIV, and it is resistant to many antibiotics. With the goal of exploring possible alternative treatments, we tested essential oils (EOs) for their efficacy as antimicrobial agents against $\mathrm{H}$. ducreyi.

Methods: We determine the minimum inhibitory concentration (MIC) of Cinnamomum verum (cinnamon), Eugenia caryophyllus (clove) and Thymus satureioides (thyme) oil against 9 strains of H. ducreyi using the agar dilution method. We also determined the minimum lethal concentration for each oil by subculturing from the MIC plates onto fresh agar without essential oil. For both tests, we used a 2-way ANOVA to evaluate whether antibiotic-resistant strains had a different sensitivity to the oils relative to non-resistant strains.

Results: All 3 oils demonstrated excellent activity against $H$. ducreyi, with MICs of 0.05 to $0.52 \mathrm{mg} / \mathrm{mL}$ and MLCs of $0.1-0.5 \mathrm{mg} / \mathrm{mL}$. Antibiotic-resistant strains of $\mathrm{H}$. ducreyi were equally susceptible to these 3 essential oils relative to non-resistant strains $(p=0.409)$.
\end{abstract}

Conclusion: E. caryophyllus, C. verum and T. satureioides oils are promising alternatives to antibiotic treatment for chancroid.

Keywords: Haemophilus ducreyi, Chancroid, Essential oil

\section{Background}

Haemophilus ducreyi, a Gram-negative coccobacillus, is a strict human pathogen responsible for the development of chancroid, which is a sexually transmitted infection (STI) that causes the formation of genital ulcers 4-10 days after acquisition of the bacteria and persists in some cases for 1-3 months. While relatively rare in the United States, chancroid is more prevalent in regions of Africa, Asia and Latin America due in part to the limited availability of health-care resources such as antibiotics. As there is no current vaccine for chancroid, treatment focuses on the use of antibiotics, typically $500 \mathrm{mg}$ of ciprofloxacin administered orally twice a day for three days, although azithromycin, ceftriaxone, and erythromycin are also common [1].

Although no one strain of $H$. ducreyi demonstrates the wide range of and high degree of antibiotic resistance that is found in some bacteria, an increasing number of strains of $H$. ducreyi have developed some degree of antibiotic

\footnotetext{
* Correspondence: thumphre@allegheny.edu

Allegheny College Department of Biology, 520 N. Main St., Meadville, PA 16335, USA
}

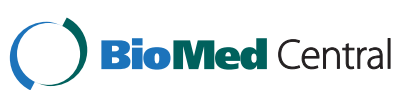

(C) 2014 Lindeman et al.; licensee BioMed Central Ltd. This is an Open Access article distributed under the terms of the Creative Commons Attribution License (http://creativecommons.org/licenses/by/2.0), which permits unrestricted use, distribution, and reproduction in any medium, provided the original work is properly credited. The Creative Commons Public Domain Dedication waiver (http://creativecommons.org/publicdomain/zero/1.0/) applies to the data made available in this article, unless otherwise stated. resistance [2]. Beginning in the 1970's, strains of H. ducreyi emerged that possessed resistance to penicillin and its derivatives [3]. Subsequently, strains of $H$. ducreyi demonstrated resistance to sulfonamides, aminoglycosides, tetracyclines, and chloramphenicol [4]. The development of antibiotic resistance in $H$. ducreyi is of particular concern given the connection between HIV-1 and chancroid [5]. Genital ulcer diseases (GUDs), which include chancroid, are a known cofactor for HIV transmission; people with a GUD are 50-300 times more likely to contract HIV per unprotected act of vaginal intercourse. In many areas where HIV is prevalent, chancroid is the most common GUD [5]. Therefore, treatment of chancroid seems likely to help prevent the spread of HIV, especially in impoverished regions of the developing world with poor health care institutions.

With the increasing resistance of strains of $H$. ducreyi to antibiotics currently in use and the threat that chancroid contributes to the spread of HIV, it seems prudent to search for alternatives to the current methods of treatment for chancroid. One such alternative that has shown promise in the treatment of other bacteria but has never been 
tested on $H$. ducreyi is the use of essential oils, a chemically diverse group of plant-derived compounds, many of which have antibacterial properties [6]. Importantly, the antibacterial activity of essential oils is as potent against bacterial strains with antibiotic resistance as their nonresistant counterparts [7]. For example, MRSA is susceptible to thyme white oil, lemon oil, lemongrass oil, and cinnamon oil [7]. The susceptibility of STIs to essential oils is not well studied, although Neisseria gonorrhoeae is susceptible to the essential oil of Croton gratissimus [8].

Based on the antibacterial effects of a wide variety of essential oils, we determined the minimum inhibitory concentrations (MICs) and minimum lethal concentrations (MLCs) of E. caryophyllus, C. verum and T. satureioides using the agar dilution method $[7,9]$. Based on our results, $H$. ducreyi is more susceptible to $C$. verum, $T$. satureioides and E. caryophyllus than any of the control organisms, making all of three oils excellent candidates for clinical trials in future studies.

\section{Methods}

\section{Selection of bacterial species}

Nine strains of Haemophilus ducreyi were chosen to reflect the varying degrees of antibiotic resistance found clinically: $35000 \mathrm{HP}, \mathrm{CIP} 542, \mathrm{HMC} 46\left(\mathrm{Pc}^{\mathrm{R}}, \mathrm{Tc}^{\mathrm{R}}, \mathrm{Cm}^{\mathrm{R}}\right)$, HMC48 $\left(\mathrm{Pc}^{\mathrm{R}}, \mathrm{Tc}^{\mathrm{R}}, \mathrm{Cm}^{\mathrm{R}}\right)$, HMC56 $\left(\mathrm{Pc}^{\mathrm{R}}, \mathrm{Tc}^{\mathrm{R}}\right)$, HMC88 $\left(\mathrm{Pc}^{\mathrm{R}}, \mathrm{Tc}^{\mathrm{R}}, \mathrm{Cm}^{\mathrm{R}}, \mathrm{TMP}^{\mathrm{R}}, \operatorname{Str}^{\mathrm{R}}, \operatorname{Kan}^{\mathrm{R}}\right), \mathrm{HMC} 49, \mathrm{HMC53}$ $\left(\mathrm{Pc}^{\mathrm{R}}, \mathrm{Tc}^{\mathrm{R}}, \mathrm{Cm}^{\mathrm{R}}\right)$ and HMC112 [10]. In addition, Escherichia coli K-12, Pseudomonas aeruginosa 49189 (ATCC, Manassa, VA, USA), Lactobacillus reuteri HM-102 (BEI Resources, Manassas, VA, USA), and Staphylococcus aureus strain +4651 (Presque Isle Cultures, Erie, PA, USA) were used as controls. All strains of $H$. ducreyi were provided courtesy of Stanley Spinola (Indiana University School of Medicine) or Patricia Totten (University of Washington). S. aureus and E. coli were chosen as positive controls because all selected essential oils are effective bacteriostatic agents against both [9]. P. aeruginosa was chosen as a control representing relative resistance to essential oils, being resistant to most essential oils except cinnamon and oregano [9]. L. reuteri was chosen as a representative of the many Lactobacillus species that make up the vaginal flora. The susceptibility of $L$. reuteri is unknown, although Lactobacillus strains are resistant to tea tree oil concentrations up to $2.0 \%$ [11].

\section{Essential oils tested}

The following pure essential oils were selected for analysis: Eugenia caryophyllus (clove), Cinnamomum verum (cinnamon), and Thymus satureioides (thyme). All essential oils were purchased from NOW Foods (Bloomingdale, IL, USA).
Determination of minimum inhibitory concentrations (MICs)

MICs were determined by the agar-dilution method based on the Clinical and Laboratory Standards Institute guidelines $[6,8]$. Each essential oil was diluted in sterile $0.15 \%$ agar solution [9]. Twofold serial dilutions of each essential oil were performed to create dilutions of each essential oil ranging from $2.5 \%$ to $0.001 \%(\mathrm{mg} / \mathrm{mL}$ varies by density of each oil). Chocolate agar plates were inoculated and incubated as previously described.

L. reuteri was grown at $33^{\circ} \mathrm{C}$ in a $10 \% \mathrm{CO}_{2}$ incubator. All other control organisms were grown at $37^{\circ} \mathrm{C}$. After the initial screen, the range of concentrations tested in subsequent assays was narrowed down to the three concentrations nearest to the apparent MIC. Each strain/ concentration combination was tested in triplicate for each assay, and the entire assay was repeated three times for each of the strains of $H$. ducreyi tested, as well as for all control organisms. MICs were defined as the lowest concentration of oil for which there was no visible bacterial growth on any of the plates assayed [9].

\section{Determination of minimum lethal concentrations (MLCs)}

Subcultures were taken from each of the chocolate agar plates used in the MIC assays that exhibited no growth after 36 hours. A sterile wire loop was used to scrape the surface of the agar and any bacteria present were thus transferred to a fresh chocolate agar plate that lacked any essential oil and incubated for 24-72 hours. The lowest concentration of an essential oil from which the bacteria failed to grow within 24-72 hours (depending on the relative normal growth rates of each strain of bacteria tested) after being transferred to a new chocolate agar plate was defined as the MLC.

\section{Data analysis}

Each phase of this study was performed in triplicate. Mean values for the MICs and MLCs were calculated for each essential oil. A 2-way ANOVA was used to analyze the differences in MIC and MLC between resistant and nonresistant strains. Differences in values of $\mathrm{p}<0.05$ were considered significant. Data were analyzed with IBM SPSS Statistics, Version 19 (IBM Corporation, Armonk, NY).

\section{Results and discussion}

MICs were determined for C. verum, E. caryophyllus, and T. satureioides using the agar dilution method. E. caryophyllus had the most potent antibacterial effects out of the essential oils tested, with an MIC of $0.085 \pm 0.03 \mathrm{mg} / \mathrm{mL}$ (mean \pm SD) and an MLC of $0.14 \pm 0.07 \mathrm{mg} / \mathrm{mL}$ (mean \pm $\mathrm{SD}$ ). However, both $C$. verum and $T$. satureioides were relatively effective as well, with MICs of $0.23 \pm 0.14 \mathrm{mg} / \mathrm{mL}$ and $0.29 \pm 0.11 \mathrm{mg} / \mathrm{mL}$ (mean $\pm \mathrm{SD}$ ), respectively (Table 1 ). According to Ríos and Recio's criteria [6], E. caryophyllus is the most promising oil as the MIC and MLC for most 
Table 1 MICs $^{\mathrm{a}}$ and MLCs ${ }^{\mathrm{b}}$ of essential oils against antibiotic resistant and sensitive strains of $H$. ducreyi

\begin{tabular}{|c|c|c|c|c|c|c|}
\hline \multirow[b]{2}{*}{ Organism } & \multicolumn{2}{|c|}{ E. caryophyllus } & \multicolumn{2}{|c|}{ C. verum } & \multicolumn{2}{|c|}{ T. satureioides } \\
\hline & MIC & MLC & MIC & MLC & MIC & MLC \\
\hline \multicolumn{7}{|l|}{ H. ducreyi } \\
\hline $35000 \mathrm{HP}$ & 0.104 & 0.260 & 0.103 & 0.260 & 0.460 & 0.460 \\
\hline HMC112 & 0.050 & 0.104 & 0.103 & 0.260 & 0.230 & 0.230 \\
\hline $\mathrm{HMC} 46^{\mathrm{C}}$ & 0.050 & 0.104 & 0.520 & 0.520 & 0.230 & 0.460 \\
\hline $\mathrm{HMC} 48^{\mathrm{C}}$ & 0.104 & 0.104 & 0.260 & 0.520 & 0.230 & 0.230 \\
\hline $\mathrm{HMC} 56^{\mathrm{C}}$ & 0.050 & 0.104 & 0.260 & 0.260 & 0.230 & 0.460 \\
\hline $\mathrm{HMC} 88^{c}$ & 0.104 & 0.104 & 0.260 & 0.260 & 0.230 & 0.460 \\
\hline $\mathrm{HMC} 49^{\mathrm{C}}$ & 0.104 & 0.104 & 0.260 & 0.260 & 0.460 & 0.460 \\
\hline $\mathrm{HMC} 53^{\mathrm{C}}$ & 0.104 & 0.260 & 0.260 & 0.260 & 0.230 & 0.230 \\
\hline CIP542ATCC & $N D^{d}$ & $N D^{d}$ & 0.050 & 0.050 & $N D^{d}$ & $N D^{d}$ \\
\hline \multicolumn{7}{|l|}{ Controls } \\
\hline E. coli & 2.6 & 2.6 & 25.8 & 25.8 & 4.6 & 4.6 \\
\hline S. aureus & 2.6 & 2.6 & 10.3 & 25.8 & 4.6 & 4.6 \\
\hline$P$. aeruginosa & 5.2 & 10.4 & 5.2 & 5.2 & 9.2 & 9.2 \\
\hline L. reuteri & $\geq 2.6$ & $\geq 2.6$ & 5.2 & 10.3 & 4.6 & 4.6 \\
\hline
\end{tabular}

MIC and MLC are reported in $\mathrm{mg} / \mathrm{mL}$. For all strains shown, $\mathrm{n}=3$.

${ }^{a}$ Minimum inhibitory concentration (MIC) is the lowest concentration of oil-infused agar on which no growth occurred.

${ }^{b}$ Minimum lethal concentration (MLC) is the concentration of oil-infused agar from which no growth occurred after transfer to fresh agar without essential oil. 'Denotes resistance to penicillin, tetracycline, kanamycin, and chloramphenicol. dNot done; due to the extremely fastidious growth requirements of this strain, sufficient growth was not obtained to determine the MIC and MLC for these oils.

strains is at or below $0.1 \mathrm{mg} / \mathrm{mL}$. Interestingly, all of the control organisms had at least 10-fold higher MICs and MLCs than any of the strains of $H$. ducreyi for each of the oils tested, suggesting that these essential oils may be particularly effective against $H$. ducreyi (Table 1 ). In the MLC assay, the antibiotic resistant strains of $H$. ducreyi were equally susceptible to the essential oils as the strains without antibiotic resistance $(\mathrm{p}=0.409)$, as is the case with previous studies [7,9], (Table 1). There was no interaction between the type of oil and antibiotic resistance $(p=0.227)$.

Based on the results of this study, the essential oils of C. verum, T. satureioides, and E. caryophyllus all are potent bactericides against $H$. ducreyi. Therefore, any of these three essential oils would be a promising alternative to antibiotics. However, although the effectiveness of all essential oils tested varied based on the strain of $H$. ducreyi, for each strain we tested E. caryophyllus oil had either the lowest MLC or was tied for the lowest MLC with either C. verum or T. satureioides (Table 1). Therefore, E. caryophyllus oil in particular provides an excellent opportunity for further study.

The viability of $E$. caryophyllus oil as a potential treatment for chancroid is further supported by the results we obtained for our control organisms, particularly L. reuteri. Lactobacillus species are a large component of the flora in the female reproductive tract and play an important role in protecting the vaginal environment from invasion by foreign pathogens [12]. This is especially important in the treatment of chancroid because disrupting the Lactobacillus species in the vagina can increase the susceptibility to HIV [13]. Therefore, a suitable potential treatment for chancroid would ideally be harmless to natural flora. Although L. reuteri is a resident of the gut, rather than vagina, it was chosen as a representative of the Lactobacillus species that inhabit the vagina because it grows most readily on chocolate agar. Importantly, we found that $L$. reuteri is much more tolerant (at least tenfold higher MLCs for each oil) of C. verum, T. satureioides, and E. caryophyllus oils than $H$. ducreyi (Table 1). It is therefore likely that MLC doses of these three oils for $H$. ducreyi would have no adverse effects on host flora.

Another quality of essential oils that would make them a good alternative treatment for chancroid is their low cytotoxicity. Because chancroid is a genital ulcer disease, topical administration appears to be the most likely choice. When administered topically, essential oils have low toxicity provided they are diluted to at least $3 \%-4 \%$ in carrier oil [14]. Possible side effects of essential oils applied to the skin are confined to irritation or allergic reactions [15]. However, because the MLCs for C. verum, E. caryophyllus, and T. satureioides range from $0.01-0.05 \%$ (ca. $0.1-0.5 \mathrm{mg} / \mathrm{mL}$ ), it is unlikely that such side effects would occur (Table 1).

\section{Conclusions}

Based on the results of this study, C. verum (cinnamon), T. satureioides (thyme), and particularly E. caryophyllus (clove) oil would all make excellent candidates for an alternative treatment for chancroid that would be relatively risk free and cheaply produced. We recommend further study to assess the antibacterial activity of these oils in vivo.

\section{Abbreviations}

$\mathrm{Cm}^{\mathrm{R}}$ : Chloramphenicol-resistant; GUD: Genital ulcer disease; Kan $^{R}$ : Kanamycin-resistant; HIV: Human immunodeficiency virus; MIC: Minimum inhibitory concentration; MLC: Minimum lethal concentration; MRSA: Methicillin-resistant Staphylococcus aureus; $P C^{R}$ : Penicillin-resistant; STI: Sexually-transmitted infection; $T^{R}$ : Tetracycline-resistant; TMPR: Trimethoprim-sulfamethoxazole-resistant.

\section{Competing interests}

The authors declare that they have no competing interests.

\section{Authors' contributions}

ZL participated in the study design, data collection, statistical analysis, preparation and revision of the manuscript. MW participated in the study design, data collection and analysis. AB participated in collection and analysis of the data. TH participated in the study design, interpretation of the data and manuscript revision. All authors read and approved the final manuscript.

\section{Acknowledgements}

The authors thank Allegheny College for financial support, Milt Ostrofsky for assistance with statistics, and Erin Nawrocki for technical assistance. 
Received: 9 January 2014 Accepted: 20 May 2014

Published: 27 May 2014

\section{References}

1. Sexually transmitted diseases treatment guidelines, diseases characterized by genital, anal, or perianal ulcers. 2010: http://www.cdc gov/std/treatment/2010/genital-ulcers.htm\#chancroid.

2. Rutanarugsa A, Vorachit M, Polnikorn N, Jayanetra P: Drug resistance of Haemophilus ducreyi. Southeast Asian J Trop Med Public Health 1990, 21:185-193.

3. Brunton IL, Maclean I, Ronald AR, Albritton WL: Plasmid-mediated ampicillin resistance in Haemophilus ducreyi. Antimicrob Agents Chemother 1979, 15:294-299.

4. Morse SA: Chancroid and Haemophilus ducreyi. Clin Microbiol Rev 1989, 2:137-157.

5. Steen R: Eradicating chancroid. Bull World Health Organ 2001, 79:818-826.

6. Rios JL, Recio MC: Medicinal plants and antimicrobial activity. J Ethnopharmacol 2005, 100:80-84.

7. Warnke PH, Becker ST, Podschun R, Sivananthan S, Springer IN, Russo PA Wiltfang J, Fickenscher $\mathrm{H}$, Sherny E: The battle against multi-resistant strains: renaissance of antimicrobial essential oils as a promising force to fight hospital-acquired infections. J Craniomaxillofac Surg 2009, 37:392-397.

8. Van Vuuren SF, Naidoo D: An antimicrobial investigation of plants used traditionally in southern Africa to treat sexually transmitted infections. J Ethnopharmacol 2010, 130(3):552-558.

9. Mayaud L, Carricajo A, Zhiri A, Aubert G: Comparison of bacteriostatic and bactericidal activity of 13 essential oils against strains with varying sensitivity to antibiotics. Lett Appl Microbiol 2008, 47:167-173.

10. Haydock AK, Martin DH, Morse SA, Cammarata C, Mertz KJ, Totten PA: Molecular characterization of Haemophilus ducreyi strains from Jackson, Mississippi, and New Orleans, Louisiana. J Infect Dis 1999, 179:1423-1432.

11. Hammer KA, Carson CF, Riley TV: In vitro susceptibilities of lactobacilli and organisms associated with bacterial vaginosis to Melaleuca alternifolia (tea tree) oil. Antimicrob Agents Chemother 1999, 43:196.

12. Linhares IM, Giraldo $P C$, Baracat EC: New findings about vaginal bacterial flora. Rev Assoc Med Bras 2010, 56(3):370-374.

13. Ravel J, Gajer P, Fu L, Mauck CK, Koenig SS, Sakamoto J, Motsinger-Reif AA, Doncel GF, Zeichner SL: Twice-daily application of HIV microbicides alter the vaginal microbiota. MBio 2012, 3(6): doi:10.1128/mBio.00370-12.

14. Lis-Balchin M: Possible health and safety problems in the use of novel plant essential oils and extracts in aromatherapy. $J R$ Soc Promot Health 1999, 119:240-243.

15. Reichling J, Schnitzler P, Suschke U, Saller R: Essential oils of aromatic plants with antibacterial, antifungal, antiviral, and cytotoxic properties-an overview. Forsch Komplementmed 2009, 16:79-90.

doi:10.1186/1472-6882-14-172

Cite this article as: Lindeman et al:: Assessing the antibiotic potential of essential oils against Haemophilus ducreyi. BMC Complementary and Alternative Medicine 2014 14:172.

\section{Submit your next manuscript to BioMed Central and take full advantage of:}

- Convenient online submission

- Thorough peer review

- No space constraints or color figure charges

- Immediate publication on acceptance

- Inclusion in PubMed, CAS, Scopus and Google Scholar

- Research which is freely available for redistribution 